\title{
Petroleum composition revealed from revised programed pyrolysis and implications for lacustrine shale oil mobility and resource potential
}

\author{
MAOWEN Li ${ }^{1}$, ZHUOHENG CHEN $^{2}$, MENHUI QIAN ${ }^{1}$, \\ XiAOXIAO MA ${ }^{1}$, QIGUi JIANG ${ }^{1}$, ZHIMING LI $^{1}$ \\ ${ }^{1}$ Sinopec Petroleum Exploration and Production Research \\ Institute, 31 Xueyuan Road, Beijing 100083, China \\ (*Correspondence: limw.syky@sinopec.com) \\ ${ }^{2}$ Geological Survey of Canada, Calgary, 3303-33 Street, NW \\ Calgary, Alberta T2L 2A7, Canada
}

Understanding oil mobility in shale reservoir is critical for resource extraction in unconventional resource play, while oil composition is one of the most important factors controlling hydrocarbon productivity and ultimate oil recovery. This presentation demonstrates a kinetic decomposition method for studying oil composition characteristics from detailed examination of pyrolysis S1 peak from source rock samples. To make a full correction for evaporative loss of gaseous and light hydrocarbon in S1 during coring and sample storage, three steps were taken: 1) core samples were freezed immediately at drill site and kept at $-60 \mathrm{oC}$ ever since; 2 ) core samples were grinded using a closed, online liquid nitrogen cooled system into approximately 100 mesh immediately prior to pyrolysis analysis; 3) phase behavior and PVT analysis were introduced in the calculation. In order to demonstrate the application of proposed method, special programed pyrolysis results were compared with the routine source rock screening pyrolysis data, from a recent shale oil study well of the Eocene Qianjiang Formation in Jianghan Basin, China. We showed that (a) by reassembling corresponding activation energies, the original S1 curve can be split into groups of similar thermal evaporative property, resulting in a composition classification of free hydrocarbons in S1 when it was converted to temperature domain; (b) a full correction on the gaseous and light hydrocarbon loss in S1 permits a more precise estimation of oil composition as well as total resource; (c) the resulting oil composition grouping provides information for inferring the fraction of extractable hydrocarbon; d) oil composition varies considerably among the samples within a stratigraphic interval of 20 meters. Samples from intra salt organic-rich lamina show different compositional characteristics with much less abundance in gaseous and volatile oil compounds; while samples from inter salt interval contain large portion of volatile and light oil, indicating a promising production zone. 